\title{
The Integration of Process and Product Metallurgy in Niobium Bearing Steels
}

\author{
Steven G. Jansto \\ CBMM North America, Inc., Pittsburgh, PA 15205, USA; steve.jansto@cbmm.com; Tel.: +1-412-759-1057
}

Received: 15 July 2018; Accepted: 14 August 2018; Published: 28 August 2018

Abstract: A review of the technological integration of both the process and physical metallurgical advancements of value-added niobium $(\mathrm{Nb})$ microalloyed thermo-mechanical controlled process (TMCP) steels have evolved into the development of higher quality steels for more demanding end user requirements. The connection of process and physical metallurgy is evolving through the integration of research that is aimed at improving product quality. However, often the connection of the process metallurgical parameters is not reported, especially with industrial data. The importance of this innovative metallurgical connection is validated by the market demand for reduced fuel consumption, improved quality, and $\mathrm{CO}_{2}$ emissions in both the automotive and construction sectors. This situation has further increased the demand for new higher quality $\mathrm{Nb}$-bearing steel grades. This integrative process/physical metallurgical (IP/PM) approach applies to both low and high strength steel grades in numerous applications. Often, the transition from laboratory melted and TMCP to the production scale is challenging. The methodology, process control, and key production steps that are required during the melting, ladle metallurgy, continuous casting, thermal, and hot rolling production conditions often vary significantly from the laboratory conditions. Understanding the reasons and corrective action for these variations is a critical product development success factor. These process metallurgy parameters for the industrial melting, casting, reheating, and hot rolling of $\mathrm{Nb}$ grades are connected and correlated to the resultant microstructures, physical metallurgy, and mechanical properties. These advanced high strength steels are microalloyed with $\mathrm{Nb}, \mathrm{V}$, Ti and/or other elements, which affect the austenite-ferrite transformation. Niobium enables the achievement of substantial grain refinement when the plate or sheet is rolled with the proper reheat, hot reduction, and thermal schedule. A recently developed key metallurgical transition is in progress applying this integrative approach with the use of MicroNiobium. A reduction of Mn and C levels with the complementary refinement of the microstructural grain size through MicroNiobium additions improves the robustness of the steel to better accommodate some process metallurgy variations. Applications are evolving in lower strength steels with $\mathrm{Nb}$ to achieve complementary grain refinement.

Keywords: continuous casting; energy absorption; mechanical metallurgy; niobium; reheat process; thermo-mechanical controlled processing

\section{Introduction}

The process and physical metallurgy in conjunction with the materials science engineering connection is vital in understanding and properly executing the successful transfer from the laboratory to industrialization. The purpose of this paper, which is rarely presented, involves the introduction of the connections between the process metallurgy of production with the resultant mechanical properties and microstructure of the commercially produced bar, plate, or sheet.

Often natural procedural variations occur in the process metallurgical steps of melting, casting, reheating, and rolling. Certainly, these process metallurgical aberrations and variations affect 
microstructure and steel quality, thereby creating an environment at time for unexpected mechanical property results. For example, the influence reheat temperature, finishing temperature, laminar cooling on the runout table, and coiling temperature directly affect the resultant microstructure in the hot rolled steel. Practical experience has identified the deleterious mixed microstructures across a given product width associated with improper thermal control [1]. For example, the inhomogeneity of overcooling near the edges and 1/4-point across the width of the rolled steel can result in a martensitic microstructure. Conversely, more homogeneous cooling near the center of the sheet results in a pearlitic/bainitic microstructure. However, when the process metallurgy parameters, such as temperature, cooling homogeneity, sheet flatness, shape, and level runout table are in the proper range of the upper and lower temperature control limits, there is a high probability that the mechanical property specifications are met and/or exceeded for the customer. Therefore, less process control variability will better correlate to the laboratory steel developmental results. Congruency of the industrial process increases the probability of proper microstructures supporting the desired mechanical properties.

For example, within a continuous hot strip rolling operation, the industrial relevance of proper coiling temperature is of paramount importance. Variations in the incoming temperature of the transfer bar into the hot strip finishing mill can result in missed coiling temperatures, and hence, less than desirable properties. The influence of coiling temperature on the microstructure and mechanical properties, especially toughness, in a low carbon niobium microalloyed steel is discussed for a $\mathrm{Nb}$-Ti grade processed via the thin slab casting processing scheme. The effect of different coiling temperature on the nature and distribution of microstructural constituents (including different phases, precipitates, and dislocations) will contribute to variations in the strength-toughness relationship of these steels. In this case, the microstructure primarily consisted of fine lath-type bainite and polygonal ferrite, and $\mathrm{NbC}, \mathrm{TiC}$, and $(\mathrm{Nb}, \mathrm{Ti}) \mathrm{C}$ precipitates of size 2 to $10 \mathrm{~nm}$ in the matrix and at dislocations. However, the dominance of bainite and distribution of precipitates is a function of coiling temperature. The lower coiling temperature provides superior strength-toughness combination and is attributed to predominantly bainitic microstructure and uniform precipitation of $\mathrm{NbC}, \mathrm{TiC}$, and $(\mathrm{Nb}, \mathrm{Ti}) \mathrm{C}$ during the coiling process, as consistent with continuous cooling transformation diagrams [2]. Lower coiling temperature was favorable for the best strength toughness combination and is attributed to the uniform distribution of $\mathrm{NbC}, \mathrm{TiC}$, and $(\mathrm{Nb}, \mathrm{Ti}) \mathrm{C}$ precipitates and predominantly bainitic structure. The bainite microstructure with high density of dislocations increases strength and toughness. At the lower coiling temperature of $579{ }^{\circ} \mathrm{C}$, no cracks were found in the bend test versus at $621^{\circ} \mathrm{C}$ cracks are evident [2]. The definition of the optimal coiling temperature now helps to better define in actual operations the range of acceptable coiling temperatures through additional experiments in the laboratory. The upper and lower control limits may be defined through experiments connecting the variables that are affecting heating and cooling in actual operations with the resultant microstructure, grain size, and mechanical property performance. Note, in this example, should a temperature variation occur across the strip width resulting in hot spots approaching $621^{\circ} \mathrm{C}$, the microstructure is prone to cracking in the bend test.

The recent advances in microalloyed steel development positions the metallurgical community to incorporate an increased focus on this process and physical metallurgy synergy. However, few papers are published and more research and development in this body of knowledge is proposed and endorsed with this paper. One of the most recent major developments is the global shift to lower carbon and leaner alloy compositions to improve steel product robustness, low temperature toughness, fatigue, and improved weldability. For example, one recent development involves the application of niobium (MicroNiobium of $0.01-0.02 \%$ ) even in lower strength, structural flat and long products allowing for Mn reductions of as high as 40\% [3]. Certainly, in conventional higher strength steel sheet and plate, $\mathrm{Nb}$ additions account for the recrystallization and very fine grained microstructure, thereby improving toughness, ductility, and increased yield strength. The TMCP (Thermo-Mechanically Controlled Processing) process enables the required tensile properties with a growing trend toward leaner chemical composition designs (less than $0.10 \% \mathrm{C}$ ) and excellent toughness properties. The consequence of leaner chemical compositions, especially lower carbon content and 
lower carbon equivalent, enhances mechanical properties, fabrication, and weldability, as well as hot rolling robustness.

\section{Materials and Methods}

For the early detection of the cause of quality anomalies and the expedition of manufacturing process management, a quality and operation management system are critical for the proper evaluation and analysis of quality problems [4]. A system has been further enhanced for microalloy steel development encompassing all of the production steps with a strong focus upon $\mathrm{Nb}$-containing steel processability. The materials encompass numerous products within the automotive, energy and structural segments. The basis for this multi-variant process control approach is necessary during the root cause analysis of quality for melting, casting, and rolling. For example, at the Basic Oxygen Furnace (BOF) or Electric Arc Furnace (EAF) or Ladle Metallurgy Furnace (LMF), process metallurgy control issues affect oxygen, nitrogen, and hydrogen. Proper slag chemistries, tapping, and tundish temperatures affect continuous casting quality, metal breakout control, and crack susceptibility. In the hot rolling step, reheating performance and hot deformation schedules play a significant role in the generation of non-uniform grain size, poor surface quality, segregation, and overall excessive variations in mechanical properties across the sheet width and/or through the plate or sheet thickness [5].

A series of steel production steps are schematically and sequentially illustrated in Figure 1 for an integrated steel operation producing continuous cast slabs, which are then hot rolled into finished coils for further processing.

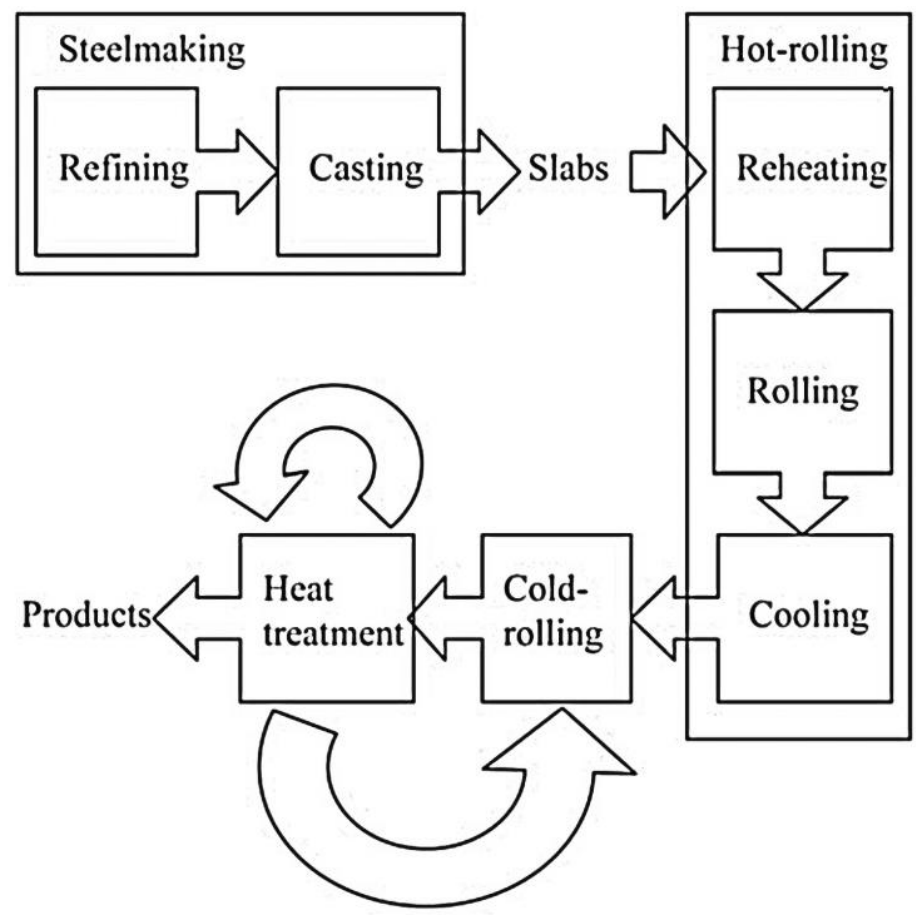

Figure 1. Schematic of conventional slab to finish coil production process (reproduced from [4], with permission from the authors, 2013).

In the BOF or EAF steelmaking process, the chemical composition of the material is adjusted, and intermediate products, called slabs, are continuously cast for this production scheme example. In the hot-rolling process, the slabs are heated to the specified temperature in the reheating process; then, they are subjected to plastic deformation in the hot rolling process to obtain the specified shape and dimensions. During the cooling process, the desired microstructure and mechanical properties of the steel material are induced into the product by application of specific cooling rates 
and patterns to achieve the specified finishing and/or coiling temperature. In the cold-rolling process and heat-treatment process, the microstructure and mechanical properties of the product are further adjusted, being dependent upon the end-user specifications. There exists a trend to eliminate heat treatment to reduce the operational cost and skip a step in the operation, thereby improving throughput. The process steps illustrated in Figure 1 are the basis where root cause analysis is often performed by the steel producer when the process is not in control and mechanical properties are deleteriously affected. Often associated with multi-variant process parameters that are out of their upper and lower process-control limit, desired mechanical properties may not be achieved. End user quality problems may result in cracks, poor formability, poor toughness, poor weldability, and inconsistent material performance.

To date, an application example in the steel industry while using the technique is a monitoring system for continuous casting, i.e., one of steel production processes, to prevent breakouts has been reported [6]. It is a system for a single process. However, how to manage the quality and operation conditions of multiple processes have not been solved. Numerous models continue to be developed to better comprehend each process step or a process micro-step within one piece of equipment. Although some incremental progress has certainly been achieved for process steps, the challenge remains the multi-variant nature of the problem containing hundreds of variables that interact with each other [7]. Process metallurgy variables within the steelmaking step that affect microalloy (including niobium-containing) steel quality involves: (1) tapping temperature, (2) improper $\mathrm{N}, \mathrm{O}$, and $\mathrm{H}$ levels, (3) poor slag partitioning, (4) BOF end-point contents, and (5) temperature control. The conditions, which mainly affect quality indices, are the contents of alloying elements of the material, which are adjusted in the steelmaking process, and the temperatures of the material in the production processes. The primary process metallurgical variables within the hot rolling operation that may affect steel quality involves: (1) reheat furnace temperature, time, stoichiometric air to gas ratio, and overall combustion efficiency, (2) refractory conditions, (3) deformation reduction schedule, (4) thermal regime performance, and (5) hot roll geometrical factors (i.e., shale, flatness, and gauge profile) [8]. The third major operation involves cold rolling. This operational effect on microalloy bearing steel quality is intimately related to the incoming hot roll strip, sheet and plate mechanical property quality and geometrical measures. Specific factors include: (1) yield-to-tensile strength variability across the width and through the thickness, (2) formability and ductility, (3) impact toughness, (4) surface quality, and (5) gauge and shape profile. Finally, the coating of the cold rolled steel and various heat treatments for both cold roll and hot rolled products can affect microalloy-containing steel quality. Coatings may involve aluminized, galvanized, and galvanized annealed products to name a few. The operational and metallurgical relationships for each of the steelmaking steps described are intimately connected to the primary process metallurgy variables that governs the resultant physical metallurgical mechanisms that result in strength, ductility, fatigue, toughness, and robustness performance.

There are numerous process variables in actual operations that have a differential effect on the resultant product quality and behavior in-service. Because this is a general purpose technique, its scope of application is currently being expanded to quality, metallurgical and operation management in various other processes where the monitoring load is high and inferior quality needs to be detected with more sensitively due to environmental changes, i.e., more severe customer requirements and more diverse microalloyed products. Within the field of advanced engineering mathematics, the effects of numerous variables on each other at different operational states is a fruitful area of research. The study and integration of actual production data under variable operational conditions and its resultant microstructure and product quality is of extreme significance and need for the steel industry. The bridge between the laboratory and production line can be connected through the physical and process metallurgy synergies that are outlined in the next three industrial case examples.

Three specific industrial process and physical metallurgical industrial cases are presented to reinforce the process and physical metallurgy synergistic approach. The first industrial case involves the relationship between steelmaking and continuous casting process metallurgical variables. 
It connects the slab surface and internal quality and stress-strain behavior with a keen focus on hot ductility and transverse cracking of microalloyed grades [9]. The second industrial case involves the connection between the reheat furnace process variables and the hot roll deformation step, resulting in its effects on austenite and ferrite grain size, recrystallization, desired microstructure, and impact toughness performance [10]. The third industrial case relates the improved quality and the cost effectiveness of Low Manganese-MicroNiobium hot rolled product [3]. These cases provide examples of both metallurgical and methodological approaches that provide an underpinning for application of such analysis for other iron and steelmaking production processes and different mill configurations.

\section{Results and Discussion}

\subsection{Steelmaking and Continuous Caster Industrial Microalloy Hot Ductiltiy Industrial Case Example}

Five major process metallurgy-physical metallurgy relationships were derived from the comprehensive global hot ductility study. Based upon the process metallurgy data supplied by the industrial partners, it was determined that the hot ductility and stress strain behavior are closely related to; (1) deleterious effect of very high tap temperatures, (2) the positive effect of controlled superheat, (3) positive effect of maximization of casting speed, (4) excessive mould level fluctuation, and (5) deleterious effect of high secondary cool zone temperatures. A chemistry comparison of different combinations of process metallurgy parameters to the hot ductility data and propensity for cracking showed it to be more related to the carbon content than the microalloy composition [9].

The addition of a single- or multi-microalloy chemistry will affect the hot ductility behavior in a laboratory test measure percent reduction in area (\%RA) in a hot tensile test in the Gleeble. The \%RA is then related to the perceived crack propensity. However, the hot ductility performance in actual practice exhibits a contrary result when compared to laboratory generated heats. The hot ductility behavior of these industrially produced microalloy steel heats result in excellent surface quality at quite low \%RA (10-15\%) and crack-free slab quality. The incongruence of the \%RA and propensity for cracking and predicted poor hot ductility behavior in the laboratory is not seen at the industrial caster. The results are validated through the analysis of the stress strain curves that are generated from industrial samples via hot tensile tests at the caster unbending temperature. The relationship between the equiaxed chill thickness of the solidifying slab in the casting mould and the distance of the mixed grain zone below the surface plays a key role in the propensity for cracking.

The sample family in this study [9] includes microalloyed ( $\mathrm{Nb}, \mathrm{V}$, and /or Ti) low carbon grades, peritectic grades, and medium carbon grades. The selected range of steel chemistries represents grades some global steel producers observed occasional surface related defects and transverse cracking. In several of the investigated cases for this research, steelmaking, caster machine, and rolling parameters have been furnished from the steel companies who provided samples, such that the ductility test conditions will simulate the actual caster conditions. The area of study involves the unbending section of the caster in the temperature range of $700{ }^{\circ} \mathrm{C}$ to $950{ }^{\circ} \mathrm{C}$ The unbending section of the continuous caster imposes the highest strain on the solidifying section of the slab or billet as it is processed. The strain is directly related to the metallurgical radius of the caster, which varies from mill to mill. The smaller the metallurgical radius (i.e., curvature of the bend) then the higher the imposed strain on the solidifying strand. Figure 2 below illustrates the location of the unbending section of the caster. 


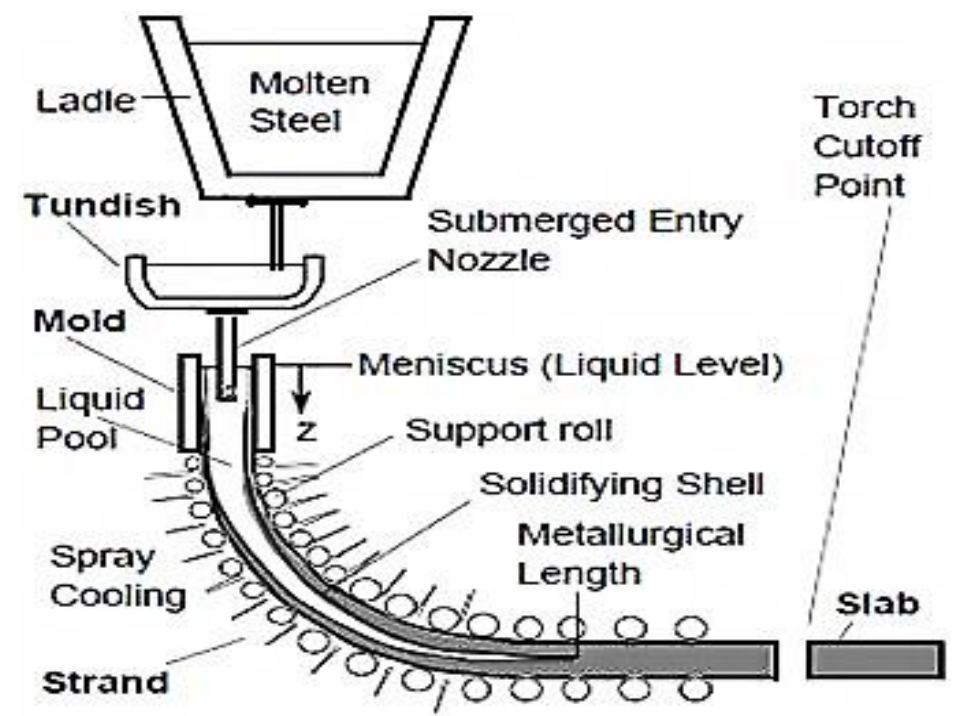

Figure 2. Detailed schematic of thick slab continuous caster (reproduced from [11], with permission from Iron \& Steel Society, 1997).

Since the typical temperature through the unbending section of the caster is between 700 to $950{ }^{\circ} \mathrm{C}$, most of the hot ductility \%RA research has been in this temperature range. The hot tensile tests are performed within this temperature range at strain rates between 0.001 to $0.0001 \mathrm{~mm} / \mathrm{mm} / \mathrm{s}$ for this stress-strain curve hot tensile test analysis. This strain rate simulates the strain rates induced within the unbending section of industrial casters at typical casting speeds for the microalloyed steels. The ductility trough in this example is between $750-800{ }^{\circ} \mathrm{C}$ with approximately $20-25 \% \mathrm{RA}$ at strain rates of 0.0001 to $0.001 \mathrm{~mm} / \mathrm{mm} / \mathrm{s}$. Most industrial casters operate at casting speeds through the straightening section with a strain rate during unbending between 0.0001 to $0.001 \mathrm{~mm} / \mathrm{mm} / \mathrm{s}$ strain rate.

The microalloy compositions that were tested are shown in Table 1 and the range from $0.045 \%$ to $0.253 \% \mathrm{C}$ at various $\mathrm{Nb}, \mathrm{V}$, and / or Ti compositions. Operational data was also obtained for each slab sample. The data included casting speed, superheat, primary and secondary cooling parameters, oscillation frequency and stroke.

Table 1. Industrial sample compositions.

\begin{tabular}{ccccccccccccccc}
\hline ID & $\mathbf{C}$ & $\mathbf{M n}$ & $\mathbf{S i}$ & $\mathbf{N b}$ & $\mathbf{V}$ & $\mathbf{T i}$ & $\mathbf{M o}$ & $\mathbf{C r}$ & $\mathbf{C u}$ & $\mathbf{N i}$ & $\mathbf{A l}$ & $\mathbf{S}$ & $\mathbf{P}$ & $\mathbf{N}$ \\
\hline 1A & 0.158 & 1.45 & 0.454 & 0.041 & 0.009 & 0.004 & 0.004 & 0.04 & 0.019 & 0.04 & 0.033 & 0.002 & 0.01 & 0.005 \\
2A & 0.154 & 1.45 & 0.455 & 0.042 & 0.009 & 0.005 & 0.006 & 0.05 & 0.027 & 0.05 & 0.033 & 0.001 & 0.01 & 0.002 \\
3B & 0.074 & 1.55 & 0.209 & 0.050 & 0.073 & 0.019 & 0.005 & 0.04 & 0.035 & 0.04 & 0.035 & 0.002 & 0.00 & 0.004 \\
4C & 0.132 & 1.57 & 0.260 & 0.036 & 0.079 & 0.031 & 0.005 & 0.04 & 0.015 & 0.04 & 0.035 & 0.002 & 0.00 & 0.005 \\
5D & 0.411 & 1.68 & 0.210 & 0.002 & 0.090 & 0.017 & 0.004 & 0.05 & 0.024 & 0.04 & 0.033 & 0.007 & 0.01 & 0.006 \\
6E & 0.141 & 1.39 & 0.390 & 0.040 & 0.078 & 0.009 & 0.006 & 0.04 & 0.026 & 0.04 & 0.029 & 0.004 & 0.01 & 0.006 \\
7F & 0.142 & 0.61 & 0.640 & 0.002 & 0.007 & 0.005 & 0.497 & 1.4 & 0.016 & 0.05 & 0.039 & 0.001 & 0.00 & 0.008 \\
8G & 0.253 & 1.05 & 0.503 & 0.002 & 0.008 & 0.028 & 0.184 & 0.38 & 0.016 & 0.36 & 0.044 & 0.002 & 0.00 & 0.005 \\
9H & 0.072 & 1.49 & 0.250 & 0.036 & 0.008 & 0.015 & 0.004 & 0.04 & 0.142 & 0.38 & 0.036 & 0.002 & 0.00 & 0.005 \\
10I & 0.081 & 0.99 & 0.205 & 0.002 & 0.010 & 0.028 & 0.006 & 1.0 & 0.022 & 0.06 & 0.036 & 0.004 & 0.01 & 0.004 \\
11 & 0.072 & 1.41 & 0.189 & 0.023 & 0.010 & 0.014 & 0.007 & 0.05 & 0.023 & 0.05 & 0.035 & 0.005 & 0.01 & 0.005 \\
12 & 0.147 & 1.40 & 0.377 & 0.010 & 0.009 & 0.005 & 0.007 & 0.06 & 0.033 & 0.07 & 0.039 & 0.002 & 0.01 & 0.004 \\
13 & 0.045 & 1.90 & 0.179 & 0.084 & 0.013 & 0.098 & 0.006 & 0.04 & 0.045 & 0.05 & 0.026 & 0.002 & 0.00 & 0.006 \\
\hline
\end{tabular}

The traditional \%RA data was generated for all of the industrial samples. Figure 3 illustrates the traditional hot ductility test measure of $\%$ reduction in area for a low carbon microalloyed plate steel at $800{ }^{\circ} \mathrm{C}$. 


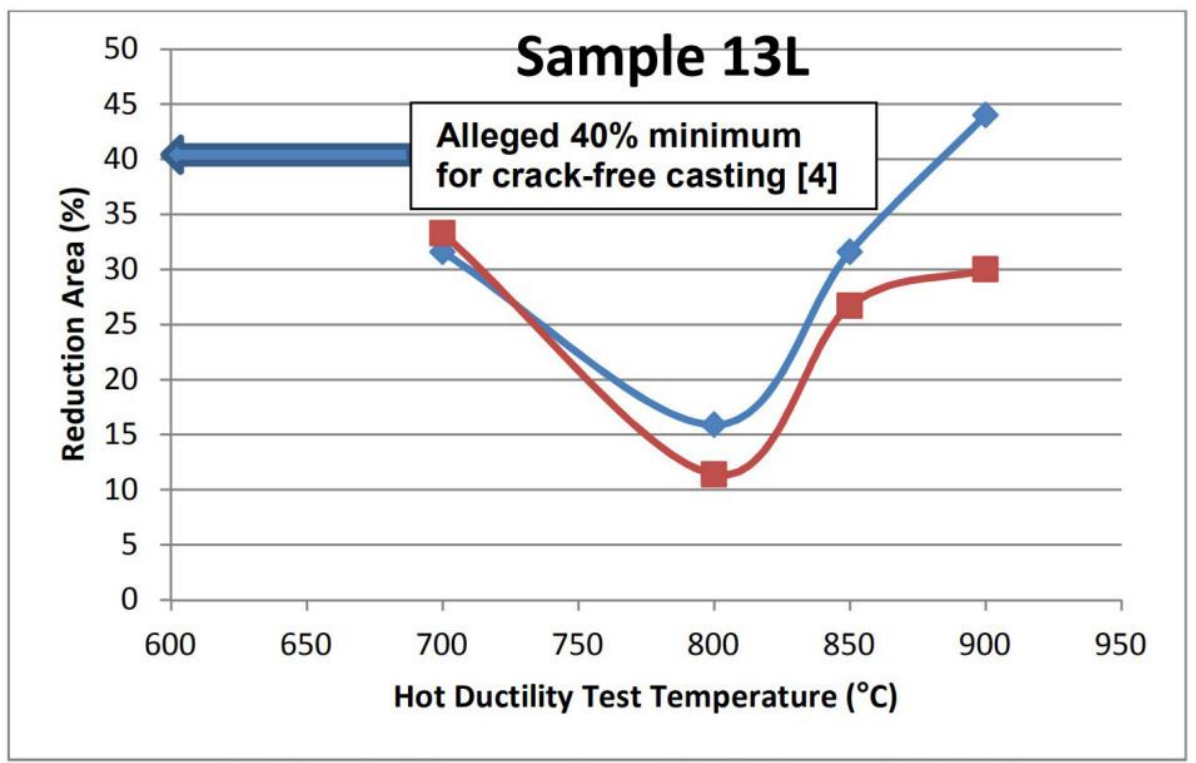

Strain rate (blue curve $)=0.001$ (red curve $)=0.0001$

Figure 3. Percent Reduction in Area Hot Ductility Test [12].

Each microalloy has a purpose to serve. With proper melting and casting parameters, these microalloy compositions are well within the capability of producing crack-free slabs, regardless of the individual microalloy, the combination of microalloys, and the carbon equivalent of the grade, even at as low as 10\%RA, yet published literature quoted $40 \%$ minimum $\%$ RA [13] to assure the crack-free casting of $\mathrm{Nb}$ bearing heats. Due to this lack of correlation between \%RA from laboratory generated heat samples and the actual performance in an industrial slab or bloom caster, it was decided to compare strain energy as a better measure for the prediction of the hot ductility behavior.

The strain rates for all of the tests simulated the actual operational strain rate at the unbending section of the casters' providing the samples for this study. The two strain rates that were employed were between 0.001 and $0.0001 \mathrm{~mm} / \mathrm{mm} / \mathrm{s}$. The raw data output of force, dynamic gauge, measurements, stress, and strain were converted into a stress strain curve for each sample (see Figure 4 as an example). Based upon the casting speeds and metallurgical radii of a given caster, solidifying slabs travel through the unbending section impose a strain rate range of 0.001 to $0.0001 \mathrm{~mm} / \mathrm{mm} / \mathrm{s}$. Therefore, these stress and strain curves were made to best accommodate the speed and strain condition actually experienced in practice. It should also be noted that all of the samples are industrial and were obtained at industrial casters along with all of the processing information. Note that at the higher strain rate, the ultimate tensile strength is $120 \mathrm{MPa}$ versus $80 \mathrm{MPa}$ (at the lower strain rate) and 0.155 strain versus 0.068 strain at UTS (Ultimate Tensile Strength), respectively. This strain energy approach has not been considered in the field of hot ductility behavior of continuous cast steels through the unbending section of the casting. Thus, this research introduces the strain energy relation to hot ductility behavior and the related significant processing variables. The strain at fracture for the 0.001 strain rate is 0.254 versus 0.135 for the lower strain rate of 0.0001 shown below in Figure 4. 

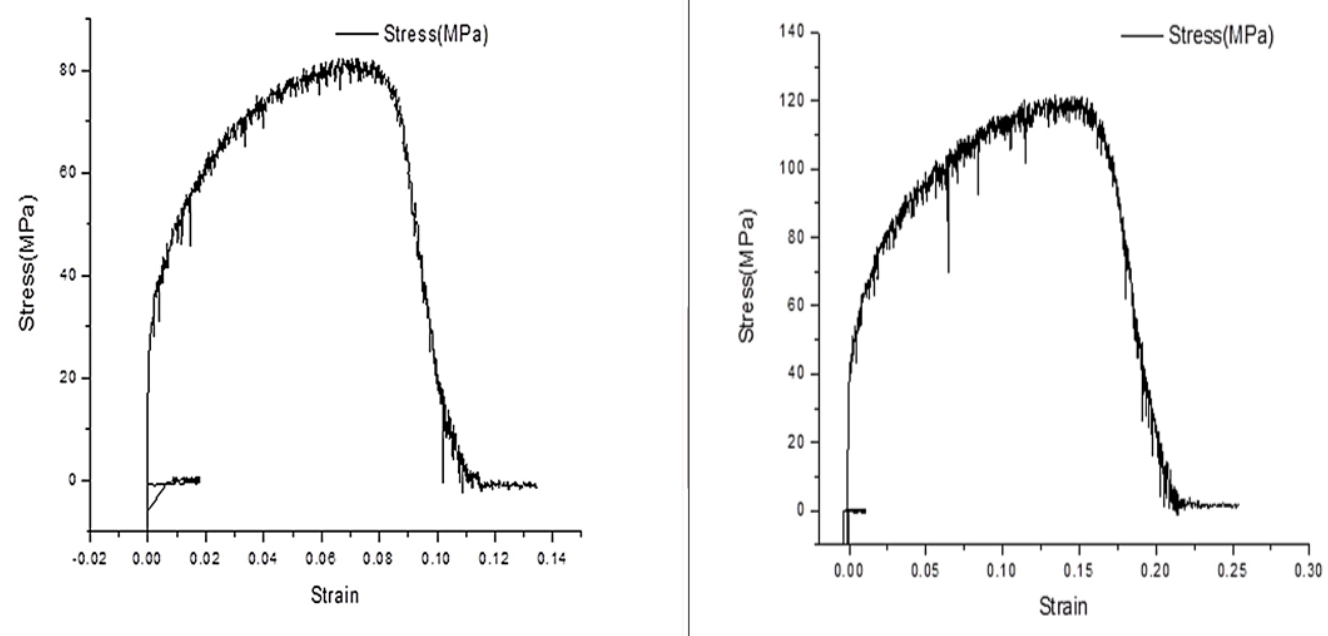

Figure 4. Sample 1A Stress Strain Curve at $800{ }^{\circ} \mathrm{C}$. (Left) 0.0001 strain rate, (right) 0.001 strain rate [12].

The area under the $\sigma-\varepsilon$ curve up to a given value of strain is defined as the total mechanical energy per unit volume ( $U^{*}$, i.e., strain energy) consumed by a material in the process of straining to that given value. The area under the stress strain curve, such as Figure 4 , is integrated per the strain energy equation, as shown by:

$$
\mathrm{U}^{*}=\left(\frac{1}{\mathrm{~V}}\right) \int \mathrm{PdL}=\int_{0}^{\mathrm{L}}\left(\frac{\mathrm{P}}{\mathrm{A}_{0}}\right)\left(\frac{\mathrm{dL}}{\mathrm{L}_{0}}\right)=\int_{0}^{\varepsilon} \sigma \mathrm{d} \varepsilon
$$

The steels that were tested in this study exhibited a range of crack free slabs at \%RA data that were considerably lower than the published $40 \%$ minimum $\%$ RA. Some researchers stipulated a required minimum $40 \%$ RA for crack-free casting of $\mathrm{Nb}$-bearing steels [13]. Yet, steels in this global study did not exhibit cracks at as low as 10-15\%RA. Thus, the strain energy (SE) has been introduced to assist in better ascertaining the hot ductility behavior of steels instead of \%RA hot ductility tests. It is postulated that the stress strain curve is a more accurate measure for a given steel's hot ductility behavior than a simple measurement of the \%RA. In order to test this postulation, all of the \%RA and strain energy data was plotted against ultimate tensile strength and strain at ultimate tensile strength.

The relationship between the steelmaking and caster operation and the resultant slab quality is related through the hot ductility behavior. This global $\mathrm{Nb}$-bearing continuous casting steel research study concludes that the incidence of slab cracking during casting is related to the steelmaking and caster process parameters [14]. These parameters include the elemental residual chemistry level, superheat variation, transfer ladle temperature stratification, mould flux incompatibility, casting speed fluctuation, mould level fluctuations, and excessive secondary cooling. The casting speed, superheat control, and primary/secondary cooling have a profound effect on the hot ductility behavior of miroalloyed steels and resultant surface quality condition. Different superheat practices have been recommended in this past research based upon the industrial sample test results [15]. Since most casters worldwide operate between a 0.0001 and 0.001 strain rate through the unbending section of the straightening section, operating closer to the faster strain rate $(0.001$ through minor increases in casting speeds) enhances both the hot ductility performance and the associated surface quality. Superheats exceeding $25^{\circ} \mathrm{C}$ are deleterious to surface quality, regardless of the chemistry.

Each operation should thoroughly understand the specific unique process metallurgy variables that have a direct influence on surface and internal quality and hot ductility behavior. Only then, 
can practices be developed accordingly to suit their micro-alloyed steel grade family of compositions, average residual levels, and customer requirements.

Although the emphasis on chemistry has been well studied, the steelmaking, solidification dynamics, and process metallurgy parameters of the actual steelmaking operations are rarely correlated to the hot ductility behavior and resultant slab surface quality [15]. In addition, most studies involve laboratory produced heats, whereas this research is based solely upon industrial produced samples with an emphasis on process parameters and solidification at different carbon levels. Continuous casting parameters, such as super heat, mold level fluctuation, heat transfer, fine grain chill zone depth, and other process performance parameters directly influence solidification behavior, and hence the surface and internal quality of the steel strand. The transition from the equixed fine grain chill zone to the mixed grain sub-surface zone is connected to the process of solidifcation. The carbon content, fine grain chill zone depth, and strain energy directly govern the hot ductility behavior and the propensity for crack formation during the unbending phase of the continuous casting process. Elements other than carbon and micro alloys exhibit secondary or tertiary root causes for crack formation. In addition to the carbon content, the synergy of the process variables affect product slab quality more than chemistry (except for carbon) [15].

Evaluation of several hundred samples at different hot tensile test temperatures resulted in the derivation of the strain energy as described in Equation (1) and the traditional \%RA. This research determined that the minimum required \%RA for crack-free casting is inaccurate and significantly overstates the \%RA that is required for crack-free castability. For example, the literature quotes $40 \%$ RA minimum for Nb-bearing steels, when in fact as low as $10 \%$ minimum RA is more than sufficient to assure crack-free casting based upon the extensive testing, operational parameter review and analysis performed in this study. Based upon this reported minimum 40\%RA [11] for crack-free casting, the implications have resulted in some alloy developers reducing or totally eliminating the selection of $\mathrm{Nb}$ for a new carbon steel development due to this published $40 \%$ RA minimum casting criterion. This situation stimulated the examination of the stress strain curve, strain at UTS, and fracture and strain energy for different steels at different unbending temperatures. A regression analysis was performed on the data. At $800{ }^{\circ} \mathrm{C}$ unbending temperature, the \%RA and strain energy was evaluated and plotted for all of the tested samples against the measured strain at the UTS Figures 5 and 6 .

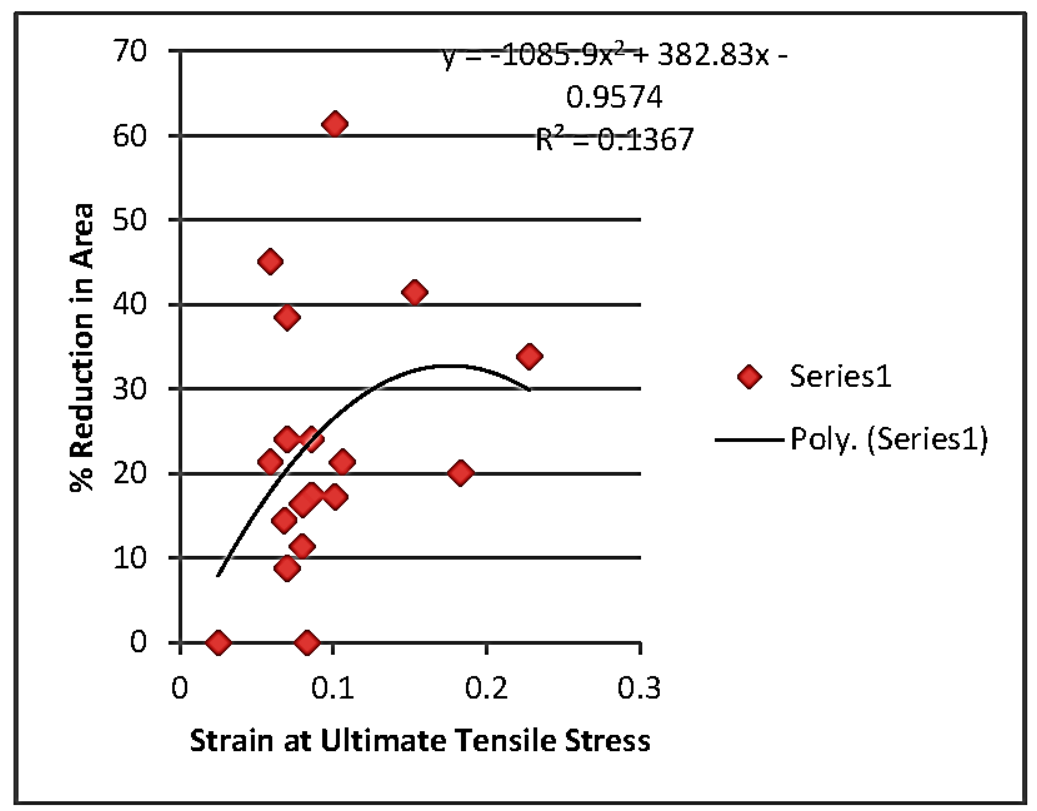

Figure 5. Percent reduction in area versus strain at ultimate tensile strength [15]. 


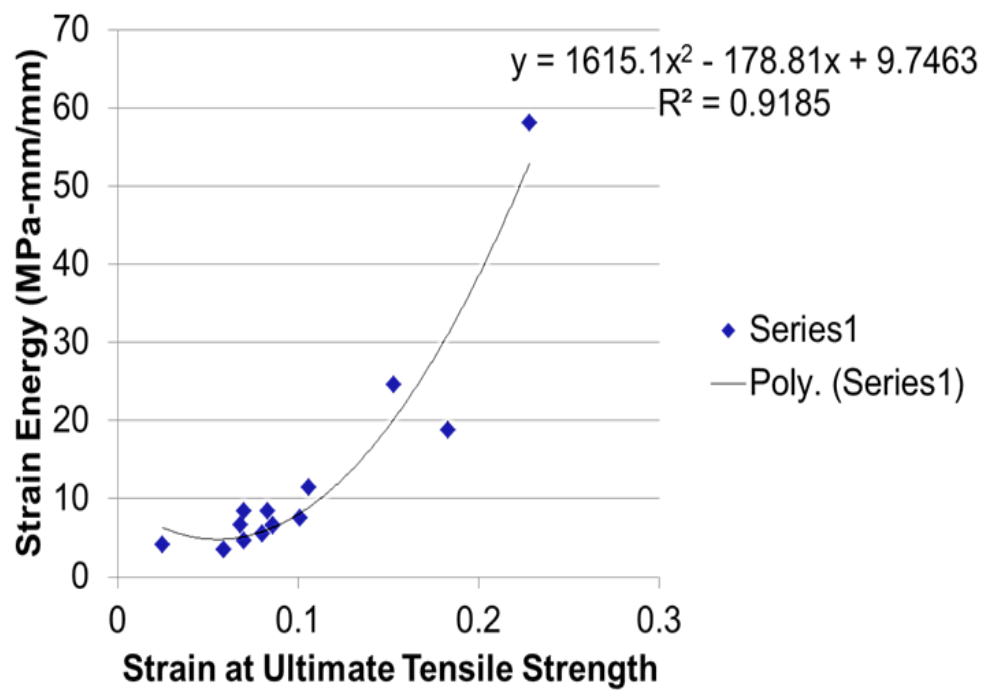

Figure 6. Strain energy vesrsus strain at ultimate tensile strength [15].

A strong correlation coefficient R-squared of 0.9185 was determined between the strain energy and strain at the ultimate tensile strength and only 0.1367 R-squared between the \% RA and the strain at UTS, as shown in Figures 5 and 6. The key factor affecting the subsurface crack propagation is the distance below the slab surface where the equiaxed chill grains transition into columnar grains. This mixed grain zone is the sub-surface crack initiation point. The strain at UTS is related to the thickness of the equiaxed chill zone and the depth of the transition grain zone below the surface. As a result of the higher correlation for both the ultimate tensile strength and the strain, it is concluded and proposed that the strain energy be defined as the preferred measure of the hot ductility characterization for different microalloy compositions. It also reinforces the conclusion that the hot ductility behavior and propensity for cracking is governed by the solidification phenomena. Future researchers are encouraged to report strain energy data when performing hot ductility tensile tests at temperature. Hence, a global strain energy database should be compiled in order to further expand. Reasons for the poor strain correlation with \%RA are related to process metallurgical factors and solidification behavior, which are typically not considered in hot tensile testing and \%RA determination. Certainly, the carbon content of the steel greatly affects the chill zone thickness. Based upon this reported minimum $40 \%$ RA [13] for crack-free casting, the implications have resulted in some alloy developers reducing or totally eliminating the selection of $\mathrm{Nb}$ for a new carbon steel development due to this published $40 \% \mathrm{RA}$ minimum casting criterion. Yet, $\mathrm{Nb}$ is a critical element for achievement of mechanical properties in hot rolled product. Based upon actual operational experience and this hot ductility study, \%RAs as low as $10 \%$ will result in crack-free casting of $\mathrm{Nb}$-bearing steels at industrial casters around the world [16].

The steels tested in this study exhibited a range of \%RA data that were considerably lower than the published $40 \%$ minimum \%RA that is required for crack-free casting of $\mathrm{Nb}$-bearing steels. Yet, these steels did not exhibit cracks. Thus, the strain energy (SE) has been introduced to assist in ascertaining the hot ductility behavior of steels. It is postulated that the stress strain curve is a more accurate measure of a given steel's hot ductility behavior than a simple measurement of the \%RA.

\subsection{Reheat Furnace Operational and Combustion Efficiency and Impact Toughness of Hot Rolled Steel Industrial Case Example}

The thermomechanical controlled processing (TMCP) of niobium bearing steels produces flat rolled products with exceptional toughness, yield-to-tensile ratios, good weldability, and excellent ductile-to-brittle transition impact behavior in a variety of applications. TMCP process metallurgy involves the triad of slab reheating practices, proper reduction schedules for appropriate recrystallization type behavior during deformation, and accelerated cooling rates (exceeding a 
minimum of $5{ }^{\circ} \mathrm{C} / \mathrm{s}$ ) on the flat rolled products. All three process metallurgy elements significantly contribute to the toughness behavior and fracture resistance to crack propagation. Often, in industrial operations, variations in the three triad parameters will offset the optimal achievement of toughness, strength, and microstructure. Figure 7 below connects the process metallurgy control of the furnace reheating and the effect on hot rolling deformation, grain size, and final plate properties.

Reheat Furnace Temperatures \& Heat Time

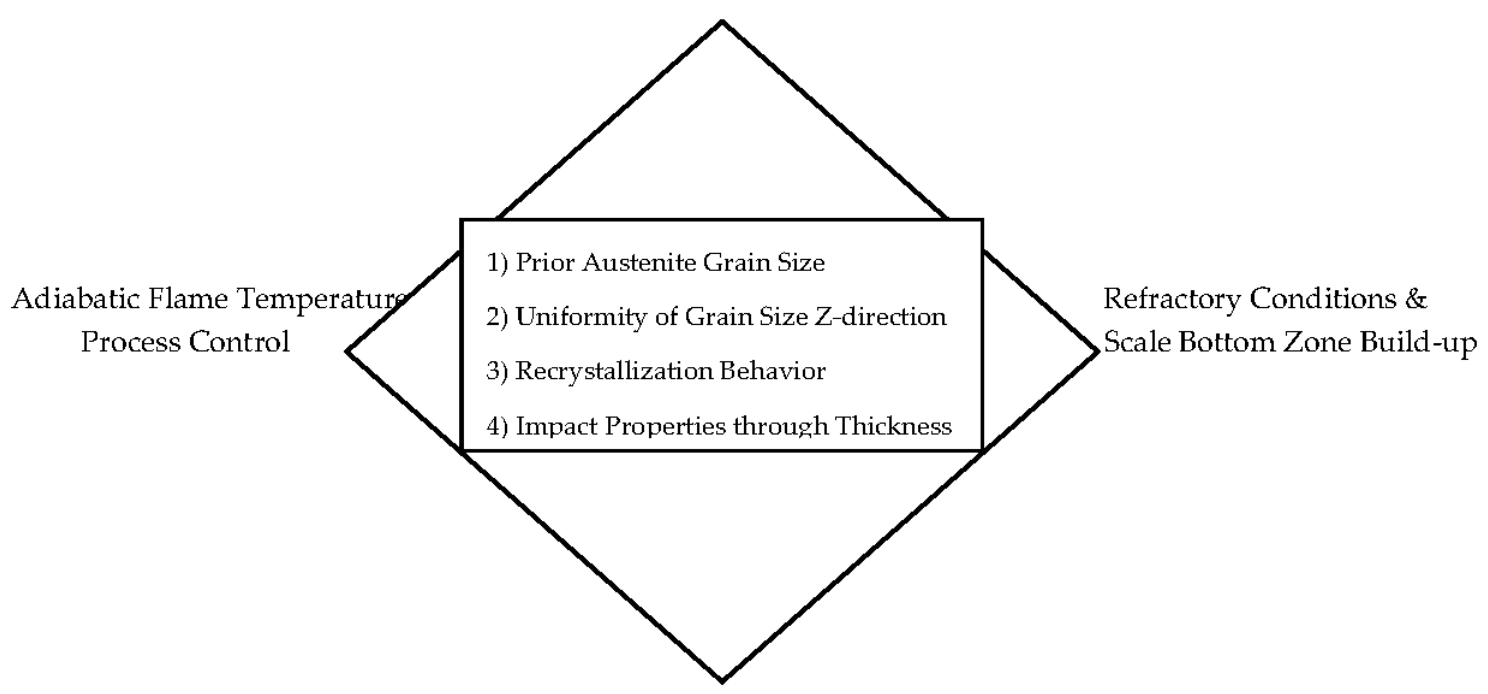

Combustion Considerations, Air-to-Gas Ratio,

Furnace Pressure, $\mathrm{O}_{2}$ in Waste Gas, Waste Gas Temperature

Figure 7. Physical and process metallurgical reheat furnace example (reproduced from [10], with permission from AIST, 2016).

This reheating step in the steelmaking process often receives low priority in the evaluation of product quality and mechanical property performance, especially the toughness through the plate thickness. Heat transfer conditions of radiation, convection, and conduction affect furnace heating efficiency. In laboratory studies, the furnace heating step is typically quite uniform, resulting in a homogeneous and fine prior austenite grain size. During production, it is much more difficult to control the uniformity of heating and heat transfer consistently along the entire length and through the thickness of the work piece. The furnace conditions are correlated to product quality via furnace process variables, such as the air to gas ratio, furnace burner condition, furnace pressure, energy efficiency, adiabatic flame temperature (AFT), and furnace refractory condition.

In the reheat furnace, the slab is actually heated via radiation from the refractory roof and sidewalls. The roof and sidewall refractory absorb heat from the flames emitted from the combustion burners. The adiabatic flame temperature (AFT) is affected by the fuel type, burner efficiency, and air to gas equivalence ratio. The highest AFT translates into higher heat input, higher production throughput, and maximum furnace efficiency. The optimum air-to-gas ratio also develops a furnace atmosphere that is conducive for good surface quality, high heat penetration into the slab, and optimal scale depth and viscosity. Figure 8 illustrates the effect of different air-to-gas ratios (i.e., equivalence ratios) on the adiabatic flame temperature for different gases. 


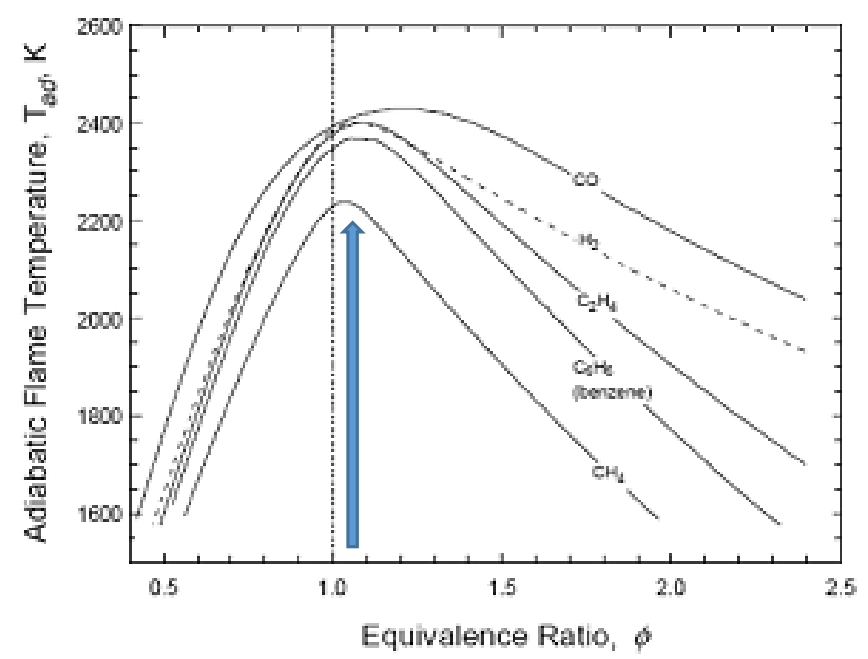

Figure 8. Adiabatic flame temperature and air-to-gas equivalence ratio [17].

Since most furnaces consume natural gas, the maximum adiabatic flame temperature of $2250{ }^{\circ} \mathrm{K}$ occurs at approximately 1.10 equivalence ratio ( $10 \%$ excess air). Under these conditions, approximately one-half of the heat that was generated from the combustion of the fuel heats the steel. As the air to gas equivalence ratio increases, combustion efficiency declines and AFT decreases. There are several operational reasons that adversely increase the equivalence ratio [18]. Several furnace factors can create higher equivalence ratios resulting in improper heating of the steel and longer heating times:

- Cracked burner orifice plates leading to sub-optimal flame temperature.

- Refractory cracks in furnace roof and/or sidewall leading to air infiltration into the furnace.

- Low furnace pressure due to inefficient combustion fan mechanical performance (bearings, out-of-balance, component wear).

- Reduced working volume in the bottom zone of preheat and reheat section due to scale buildup.

- Improper dilute oxygen enrichment at combustion burner tip.

- Scale formation and viscosity.

Most commercial fuels are hydrocarbons. According to the stoichiometric ratio for full oxidation of a fuel, air/fuel mixtures fed to a combustor are classified as:

- Lean mixtures (little fuel content, excess of air).

- Stoichiometric mixtures (with the precise or theoretical amount of fuel).

- Rich mixtures (more fuel than needed, but excess fuel will pyrolyze to small-molecule fuels, and only small molecules appear at the exhaust).

Numerous furnace operations throughout the world operate at both high reheat zone $\left(>1150{ }^{\circ} \mathrm{C}\right)$ and soak zone furnace temperature $\left(>1225^{\circ} \mathrm{C}\right)$, thereby overheating both plain carbon steels and microalloyed steels, leading to abnormal grain growth. Observations made at numerous mills around the world find high temperature furnace operation even more prevalent on higher carbon steels exceeding $0.20 \% \mathrm{C}$. The cause and effect relationship of these poor furnace heating practices have a detrimental effect on steel quality due to abnormal and variable grain size and inhomogeneous heating through the slab thickness. Coarser austenite grains translate into coarser ferrite grains in the final hot rolled product. Also, the overheating of steel results in thicker scale formation. The metallurgical consequences of thick scale formation goes beyond simple surface quality issues and translates into mechanical property variability due to the improper heating of the slabs before hot rolling. Observations that were made at numerous mills around the world find high temperature furnace operation is often prevalent at mills producing High Strength Low Alloy (HSLA) microalloyed 
steels and higher carbon steels exceeding $0.20 \%$ C. Niobium is effective in delaying austenite grain growth when high temperature overheating conditions occur. Figure 9 shows the relationship between the mass increase (i.e., scale formation), which is the weight of scale $\left(\mathrm{g} / \mathrm{m}^{2}\right)$ of slab, at $1250{ }^{\circ} \mathrm{C}$ and $1300{ }^{\circ} \mathrm{C}[19]$.

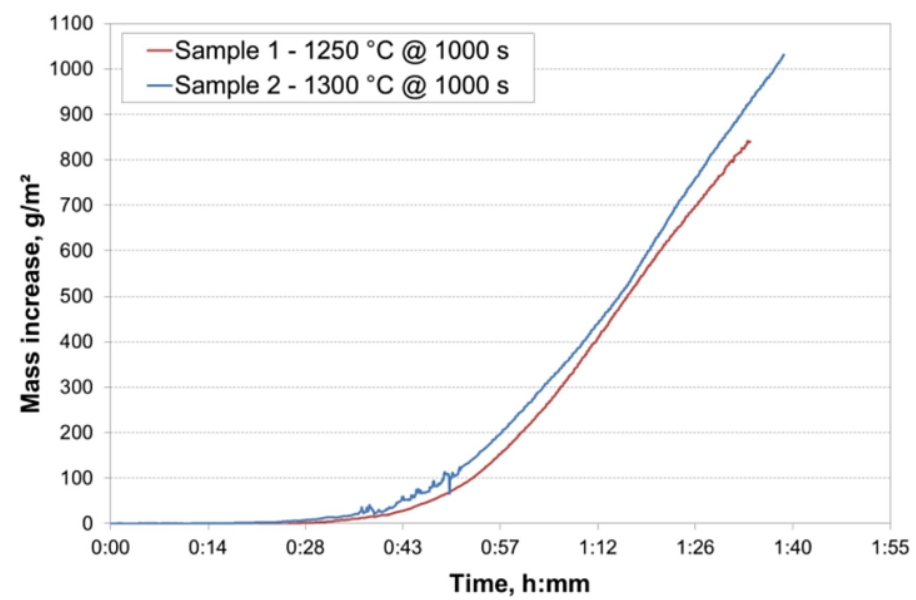

Figure 9. Increase in mass over time for oxidation at $1250{ }^{\circ} \mathrm{C}$ and $1300{ }^{\circ} \mathrm{C}$ in methane combustion atmosphere (reproduced from [19], with permission from the authors, 2014).

Within the furnace operation, heating and combustion zone temperatures are typically increased to offset the low combustion efficiency issues in an attempt to increase productivity. This approach, however, is flawed, as the slabs are not homogeneously heated. The problem is then one of sacrificing quality (i.e., mixed and coarse austenite grain size) for increased throughput. The relationship between furnace temperature, long heating times, and scale thickness are illustrated below in Figure 10 [20].

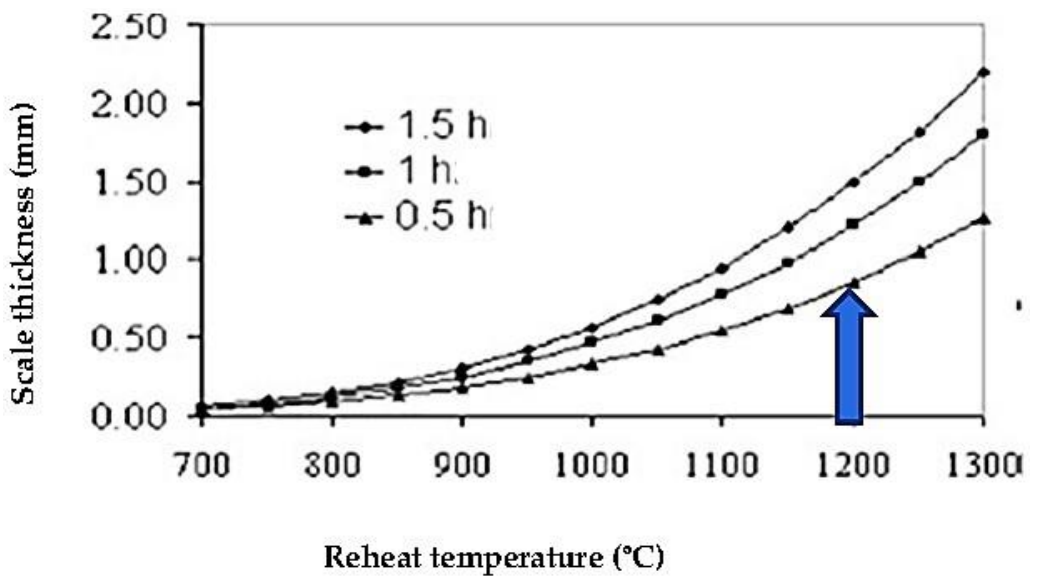

Figure 10. Scale thickness versus temperature (reproduced from [20], with permission from the authors, 2014).

Some mills increase the soak zone temperatures (optical pyrometer readings in the furnace) approaching $1250-1275^{\circ} \mathrm{C}\left(130{ }^{\circ} \mathrm{C}\right.$ in some regions of the world), which translates into steel surface discharge temperatures approaching $1225-1240{ }^{\circ} \mathrm{C}$, and thus the initiation of severe austenite grain growth. From a practical operational perspective, soak zone temperatures exceeding $1250{ }^{\circ} \mathrm{C}$ is extremely deleterious to steel surface quality, toughness, yield and mechanical property, and cost performance. The decrease in yield is due to formation of a heavy iron oxide scale. This scale can be several millimeters in thickness and converts to as much as 1 to $1.5 \%$ of yield loss. This loss in product translates into millions of dollars of scrap and reduced yield on an annual basis. 
It is apparent from Figure 10 at $1200{ }^{\circ} \mathrm{C}$ that an increase in hold time from 1.00 to $1.50 \mathrm{~h}$ will increase the scale thickness by nearly $30 \%$. Scale behaves as an insulator, and consequently, the thicker the scale then a reduction in the thermal conductance of heat absorbed by a given slab. A second factor involves the influence of the air-to-gas ratio. As the air-to-gas ratio increases, the AFT decreases and then due to more oxygen in the furnace environment, the iron oxide scale thickness will increase. Heat conductance requires longer heating times. The scale layer is an insulating layer on the slab surface, reducing the slab heat conduction efficiency. Under these conditions, longer soaking times are necessary to ensure the proper heating of the center of the slab. Longer soak times lead to increased prior austenite grain size. This variation in the heating process will significantly affect the resultant thermal homogeneity and gradient from the surface of the slab to the center of the slab, as well as the austenite grain size and distribution and ensuing recrystallization behavior.

The effects of these reheat furnace process metallurgy parameters will affect the final hot rolled microstructure and grain size. The relationship between inhomogeneous heating and the resultant mechanical properties is often not reported. The metallurgical consequence of a mixed and/or coarse austenite grain translates into variable ferrite grain size in the final rolled product. Discontinuous austenitic grain growth is directly influenced by such thermal variation conditions within the furnace that are caused by variable air to gas ratios. The effect of temperature on the prior austenite grain size is illustrated below in Figure 11 [21].

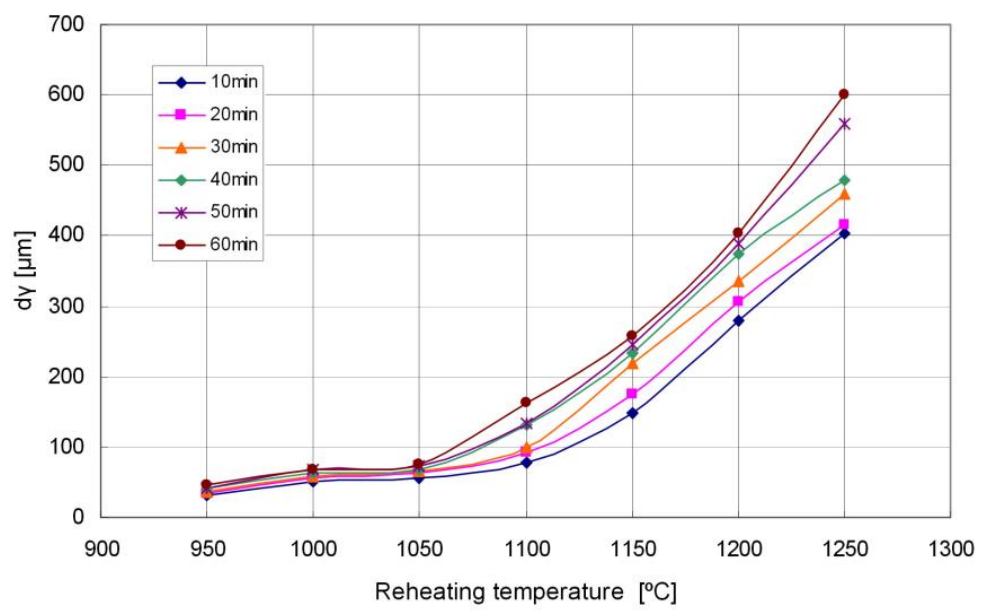

Figure 11. Austenite grain size versus temperature (reproduced from [21], with permission from the authors, 2009).

For example, the relationship between the air-to-gas ratio and the resultant austenite grain boundary may be correlated with the integration of these two figures (Figures 10 and 11). The furnace operational process metallurgy can be converted to the reheating temperature of the slab and then into the estimated austenite grain size. For example, if one section of the slab is at $1200{ }^{\circ} \mathrm{C}$ and the adjacent section is $1225^{\circ} \mathrm{C}$ due to an air to gas variation 0.05 ; then, it follows that the austenite grain size would be approximately $325 \mu \mathrm{m}$ for the $1250{ }^{\circ} \mathrm{C}$ section versus the adjacent section at $280 \mu \mathrm{m}$ grain size for the $1225^{\circ} \mathrm{C}$ region. Such differences in prior austenite grain size due to such thermal variations in combustion lead to a variable ferrite size in the final hot rolled product, and hence, variable mechanical properties.

The connection between the process metallurgy and the physical metallurgy is made in this example. The mechanical property implications involve the yield and tensile strength variability, sporadic formability, and significant impact toughness scatter through the thickness of the plate. The reheat furnace operation is receiving more attention due to its significant effect on the difference in impact properties between the $\frac{1}{4}$-point and the centerline-point in hot rolled plate. This variability increases as the plate thickness increases. 
Results of several studies confirmed the importance of proper furnace control in industrial trial production of $40-\mathrm{mm}$ plates with specified minimum yield strength (SMYS) of $450 \mathrm{MPa}$ at the 5-m hot rolling mill of Vyksa Steel Works in Russia [22]. The chemical composition of the steel was $0.06 \% \mathrm{C}$, $0.20 \% \mathrm{Si}, 1.6 \% \mathrm{Mn}, 0.03 \% \mathrm{Nb}, 0.016 \% \mathrm{Ti}$, and additions of $\mathrm{Ni}, \mathrm{Cu}, \mathrm{Cr}(\mathrm{Mo})$. A two-stage TMCP process was implemented with the proper consistent reduction parameters and various reheating modes (temperature and duration). The objective of this trial was to evaluate the effect of reheat temperature and duration time on the impact toughness behavior of a $\mathrm{Nb}$-microalloyed steel. The reheating temperatures ranged between $1100{ }^{\circ} \mathrm{C}$ and $1200{ }^{\circ} \mathrm{C}$. Slabs were held in a continuous furnace between 5 and 12 hours. Impact toughness $\left(\mathrm{Kv}\right.$ at $-20^{\circ} \mathrm{C}$ ) and drop-weight tear tests (DWTT) were measured in order to evaluate cold resistance toughness behavior from the industrial trial. [22].

Figure 12 shows the time parameter effect at a low reheat temperature of $1170{ }^{\circ} \mathrm{C}$ and the associated deterioration in toughness for slabs held over $500 \mathrm{~min}$. Also, greater than $500 \mathrm{~min}$ heating time generally exhibits lower average toughness when compared to the less than 500 min heating time.

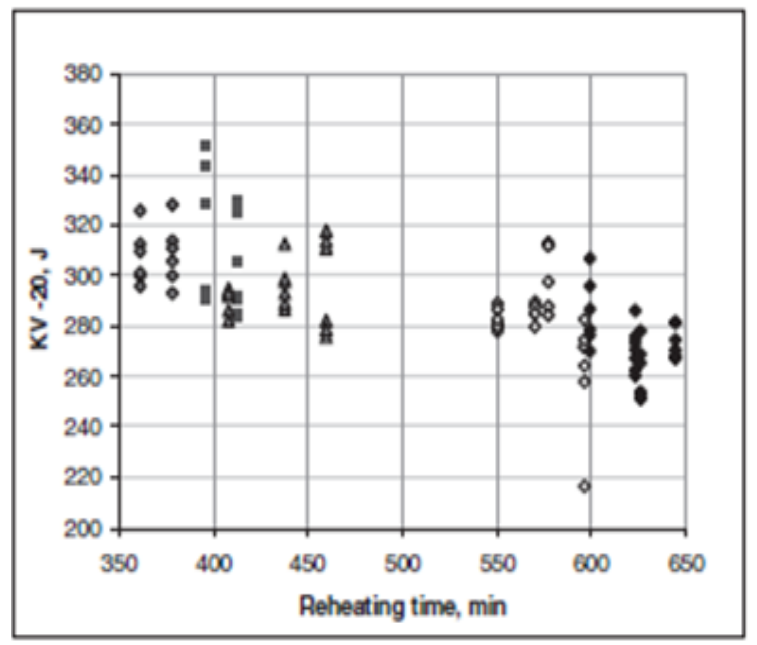

Figure 12. $\mathrm{KV}$ at $-20^{\circ} \mathrm{C}$ Joules as function of time at $1170{ }^{\circ} \mathrm{C}$ (reproduced from [22], with permission from The Minerals, Metals \&Materials Society, 2016).

The reheating is coupled with the appropriate reduction schedule to achieve proper recrystallization phenomena. This recrystallization phenomena is especially important for plate production, since even modern high-power mills cannot provide, at times, full multiple recrystallization that is aimed at refining prior coarse grained austenite structure, typical for high-temperature rolling. This blend of proper low to medium reheat practice and mechanical deformation schedule set the parameters for optimization of the finest grain size through the plate thickness. The percent drop weight tear test (DWTT) is the ultimate measure of the success or not in the final rolled plate product toughness and ductile shear behavior. The influence of reheating temperatures on \%DWTT is illustrated in Figure 13 [22].

High reheat furnace temperatures (exceeding $1225^{\circ} \mathrm{C}$ ) reduce the impact toughness and DWTT performance due to inhomogeneous heating and a coarse prior austenite grain size through the slab thickness. The proper heating temperature, time and reduction schedule is the key in optimization of the finest grain size leading to DWTT consistently exceeding $85 \%$ shear fracture even at the plate centerline. The variability in toughness from the $\frac{1}{4}$ to $\frac{1}{2}$ point of the plate can be attributed to improper furnace heating. The operational furnace parameters, such as AFT, air-to-gas ratio, $\mathrm{O}_{2}$ in the furnace atmosphere are operational contributors to poor toughness. The introduction of micro-additions of $\mathrm{Nb}$ assists in the production of a more robust hot rolled product retards austenite grain growth that is caused by reheat furnace process temperature and time irregularities [5]. 


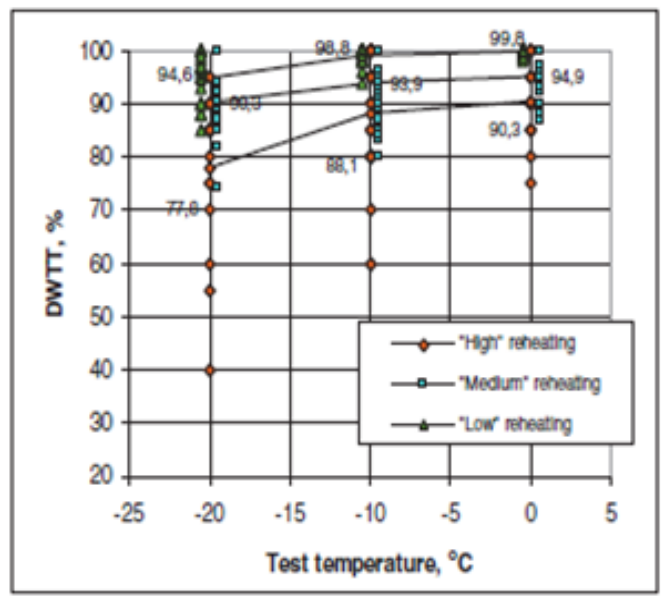

Figure 13. Shear area of drop-weight tear tests (DWTT) versus DWTT test temperature (reproduced from [22], with permission from The Minerals, Metals \&Materials Society, 2016).

\subsection{MicroNiobium Low Manganese Approach}

The new generation of value-added low carbon-low manganese microalloyed structural steel for both low and high yield strength and energy absorption applications is under development and implementation at numerous mills around the world [3]. These materials engineering considerations are shifting designers to consider new lower cost and more robust construction materials, even for low yield strength applications. These opportunities are quite positive for the steel producers who respond to the customer's needs. The civil engineering and end user community demand structural reinforcing bars, shapes, beams, and plates with improved energy absorption and fatigue properties. With more severe climatic conditions, demands for improved fire and seismic resistance, yield-to-tensile ratio consistency, improved bendability, and weldability are in the forefront. These attributes are difficult to obtain from some steel producers today with their current higher carbon microalloyed steel approaches and hot rolling practices. There already has begun a global shift from peritectic carbon $(0.11-0.16 \% \mathrm{C})$ construction grades to low $\mathrm{C}-\mathrm{Nb}$ bearing construction steels (less than $0.10 \% \mathrm{C}$ ) displacing traditional materials [23]. For example, within the construction beam and plate sector, the reduction in $\mathrm{C}$ has resulted in mechanical property improvements with a 0.015 to $0.030 \% \mathrm{Nb}$ in low carbon structural steel with an appropriate hot rolling schedule for S355 and S420 beams with improved toughness, fatigue, and fracture toughness performance.

The primary metallurgical reasons for higher production cost for this $0.11-0.16 \% \mathrm{C}$ (hypo-lperitectic) microalloyed steel grades when compared to low carbon microalloyed grades relate to negative implications at the steelmaking, casting, and hot rolling steps of the process [23]. The operational peritectic definition of numerous steel producers from around the world categorize the 0.11 to $0.16 \% \mathrm{C}$ range and more operational and quality issues occur more frequently than with less than $0.10 \%$ low carbon grades. The primary operational and metallurgical differences between the production of low carbon and peritectic grades are:

(1). Differences in solidification behavior during continuous casting.

(2). Casting requires tighter control of primary and secondary cooling for peritectic due to heat flux differences.

(3). Increased slab conditioning with peritectic grades due to uneven surface solidification resulting in a variable equiaxed chill columnar grain transition zone (EACLGZ) closer to the surface when compared to low carbon microalloyed grades [16].

(4). Maximum austenite grain size occurs in the $0.11-0.16 \% \mathrm{C}$ range.

(5). Surface quality generally worsens in hot roll product.

(6). Increased slab scarfing and potential to open cracks in peritectic grades. 
(7). Often peritectic grades are normalized heat treated to homogeneous grain size, but not necessary in low carbon grades (eliminate heat treatment).

(8). Grain size and mechanical property variability across the width and through the thickness.

(9). Peritectic grades are cast at slower speeds affecting productivity by as much as $10-20 \%$.

(10). Increase in number of transition slabs and potential downgrades.

(11). Peritectic grades tend to exhibit more internal and centerline segregation, especially as $\mathrm{Mn}$ levels increase.

If a producer opts that the peritectic approach is more cost effective, that particular mill is not properly analyzing or understanding their total cost of production for these carbon micro-alloyed steel grades. Since many end users rely on a given specification to meet their order requirements, as long as the specified chemical elements meet the composition range or maximum thresholds, the shipment is deemed acceptable. Herein, two potential problems might be experienced by the end user. Specifically, material performance variability and major carbon level differences between heats and/or multiple suppliers and service centers will result. Recent communications with end users reveal that they do not realize the negative implications to their business when the peritectic grade is processed in their operation. Concurrently, the end users of these ASTM grades are demanding structural components with less mechanical property variability and consistence. For example, properties, such as low temperature toughness, formability, bendability, weldability, fracture toughness, and fatigue performance are impaired when these higher $\mathrm{C}$ grades are applied instead of the less than $0.10 \% \mathrm{C}$ lower carbon steels.

The new generation of structural low strength steels (S235, S275, and S355) is focused upon both the peritectic and the low carbon construction grades. The ultimate goal as $\mathrm{Nb}$ concentrations are increasing in higher strength construction grades is the necessary combination of: (1) reducing the carbon to under $0.10 \%$, (2) reducing Mn levels by 0.30 to $0.40 \% \mathrm{C}$, and (3) making the proper $\mathrm{Nb}$ addition. The approach is intended to reduce the operational cost per ton in both the Melt Shop via reduced raw material cost and reduced mechanical property diverts in the hot rolling operation. The grain refinement via the $\mathrm{Nb}$-addition promotes a more homogeneous finer grain pearlite microstructure, reduced banding in the hot rolled steel at lower $\mathrm{Mn}$ and a more robust product. The lower $\mathrm{C}$, moving out of the peritectic improves weldability, and surface quality at the continuous caster. During the hot rolling of low carbon-manganese-MicroNb structural steels, the delay of the pearlite transformation leads to a finer interlammelar spacing and finer grain size due to a shorter transformation time, and thereby contributing to a strength increase even at lower $\mathrm{Mn}$ and $\mathrm{C}$ concentrations. Some of the other beneficial effects at steel producers besides reducing alloy cost from the lowering of the Mn content by as much as $0.40 \% \mathrm{Mn}$ are:

- $\quad$ Lower amount of cold additions to liquid steel (possible saving of energy).

- Lower P contamination from FeMn alloy.

- Lower Mn centerline segregation in the slab/plate.

- $\quad$ Reduced banding in hot roll microstructure.

- $\quad$ Lower carbon equivalent (better weldability).

- Improved robustness and less YS and TS scatter.

- $\quad$ Finer and more homogeneous grain size through thickness and across width.

- Improved toughness and lower DBTT (ductile to brittle transition temperature).

The low Mn-low $\mathrm{Nb} 0.16 \% \mathrm{C}$ construction steels research and development recently being commercialized involves the application of quite simple conventional rolling schedules and reheat and hot rolling practices. In the past, there was limited research into such products for two primary reasons. First, when secondary and tertiary processes, such as hot forging, drawing, and cold forging are applied to medium and high carbon steels, the effects of controlled rolling may be lost through the process. Secondly, $\mathrm{Nb}$ has a lower solubility in austenite in comparison with low carbon steels at the 
same temperature. These trials have exhibited excellent results, even in medium carbon peritectic S355 structural steels that are applied to structural plate, angles, channels, and light section supports at very economical cost. Table 2 presents the results of a low Mn-MicroNb peritectic carbon structural steel [23].

Table 2. Peritectic (0.16\%) low Mn-MicroNb mechanical properties *.

\begin{tabular}{ccccccc}
\hline Thickness & Yield Strength & Tensile Strength & Elongation & \multicolumn{3}{c}{ Impact Strength (Joules) } \\
\hline & $\mathbf{M P a}$ & $\mathbf{M P a}$ & $\mathbf{\%}$ & $-\mathbf{2 0}{ }^{\circ} \mathbf{C}$ & $\mathbf{0}^{\circ} \mathbf{C}$ & $\mathbf{2 0}{ }^{\circ} \mathbf{C}$ \\
\hline Aim & 345 & 470 & 21.0 & - & $>34$ & - \\
II-16 mm & 405 & 525 & 28.5 & 150 & 170 & 160 \\
III-16 mm & 410 & 535 & 33.0 & 150 & 170 & 160 \\
IV-40 mm & 455 & 615 & 22.0 & 100 & 155 & 180 \\
\hline
\end{tabular}

${ }^{*}$ Mn level reduced from Standard 1.45 to $1.15 \% \mathrm{Mn}$ and $0.010 \% \mathrm{Nb}$ at $0.16 \% \mathrm{C}$ (peritectic).

The intent of this industrial trial research is to further incorporate this MicroNb peritectic $\mathrm{C}$ approach in existing carbon (peritectic) compositions and replace the vanadium with niobium and make a significant reduction in the manganese level for these $345 \mathrm{MPa}$ grades. The next step is to consider a similar reduction in Mn strategy, even for lower strength steels, such as $235 \mathrm{MPa}$ and $275 \mathrm{MPa}$ as a cost reduction opportunity. The knowledge that is gained from this work illustrates the possibility of making Mn reductions and significant cost savings. There have been situations where the aim is to produce S275 and the mill actually produced S420 MPa structural grades. A second major step previously discussed is the transition from these medium carbon peritectic structural steels to less than $0.10 \%$ C grades. It is becoming apparent in S355 and S420 grades that very low manganese levels with proper reheat furnace operations and rolling practices result in easily achieving yield and tensile levels with excellent low temperature toughness, as exhibited in Table 2. The process metallurgy positively contributes to the increased strength typically expected from the additions of higher carbon and higher manganese levels. These reduced manganese and carbon levels also result in reduced alloy and processing costs, a lower carbon equivalent, and improved weldability. The Graville diagram in Figure 14 shows with the lower carbon equivalent form the carbon and manganese reduction, the chemistry moves into Zone I which requires no preheat or post-heat, which is necessary in the Zone II conditions. The MicroNiobium addition grain refinement compensates for the reduction in strength from the lower carbon and manganese levels.

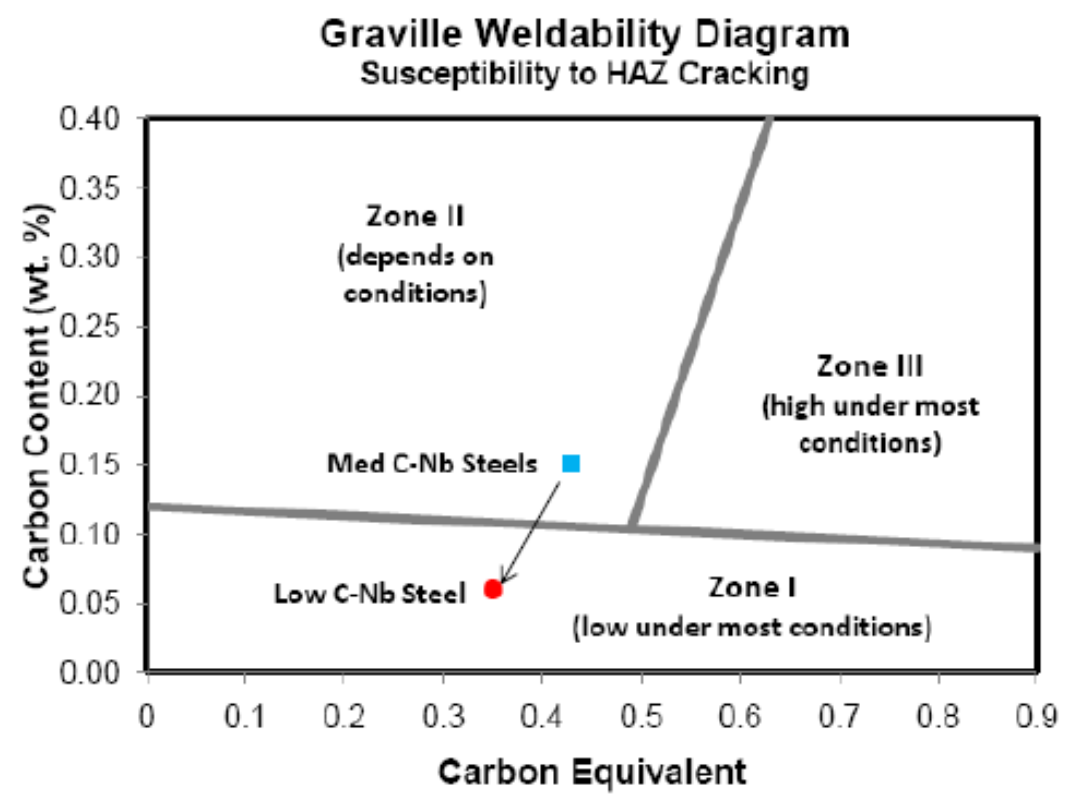

Figure 14. Graville weldability diagram [24]. 


\section{Conclusions}

The process and physical metallurgy synergy is vital in conjunction with the materials science engineering connection in understanding and properly executing the successful transfer of new and advanced steel products from the laboratory to industrialization. The integration of steelmaking, continuous casting, and hot and cold rolling is critical to properly understand the root cause process metallurgical parameters affecting the physical metallurgy of the desired products. A methodology has been presented for three industrial cases:

(1) Hot ductility behavior of $\mathrm{Nb}$-containing steels shows higher correlation between strain energy and surface quality than percent reduction in area $(0.9185$ vs. 0.1367 R-squared correlation coefficient).

(2) The effects of the reheating process operational variability during the reheating of steel slabs before rolling significantly affect austenite grain size, recrystallization behavior, and final microstructure and toughness.

(3) The new generation of value-added low carbon-low manganese MicroNiobium structural steels for both low and high yield strength and energy absorption applications are both cost effective and present improved quality.

Funding: This research received no external funding.

Conflicts of Interest: The author declares no conflict of interest.

\section{References}

1. Jansto, S. Niobium-Bearing Structural Steels for the 21st Century. TMS Niobium Bear. Struct. Steels 2010, 1, $1-26$.

2. Challa, V.S.A.; Zhou, W.H.; Misra, R.D.K.; O'Malley, R.; Jansto, S. The Effect of Coiling temperature on the Microstructure and Mechanical Properties of a Niobium-Titanium Microalloyed Steel Processed via Thin Bar Casting. Mater. Sci. Eng. A 2013, 595, 144-154. [CrossRef]

3. Jansto, S. New Generation Structural Steel Metallurgy. In Proceedings of the Materials Science \& Technology Conference, Pittsburgh, PA, USA, 8-12 October 2017.

4. Shigemori, S. Quality and Operation Management System for Steel Products through Multivariate Statistical Process Control. In Proceedings of the World Congress on Engineering 2013 (WCE 2013), London, UK, 3-5 July 2013.

5. Jansto, S. Reheat Furnace Thermodynamics, Kinetics and Combustion Considerations for TMCP Processing. In Proceedings of the THERMEC2018 Conference, Paris, France, 9-13 July 2018.

6. Dudzic, M.; Zhang, Y. On-line Industrial Implementation of Process Monitoring/Control Applications Using Multivariate Statistical Technologies: Challenges and Opportunities. In Proceedings of the IFAC Symposium on Dynamics and Control of Process Systems (DYCOPS), CD-ROM, Cambridge, MA, USA, 5-7 July 2004.

7. Kano, M. Statistical Process Control Using Process Chemometrics. Syst. Control Inf. 2004, 48, 165-170.

8. Jansto, S. Operational, Metallurgical and Technological Developments in Microalloyed Structural Plate Steels. In Proceedings of the 2nd International Symposium on Recent Developments in Plate Steels, AISTech, Orlando, FL, USA, 3-6 June 2018.

9. Jansto, S. Hot Ductility Behavior during the Continuous Casting of Niobium Bearing Steels. Ph.D. Thesis, Illinois Institute of Technology, Materials Science \& Engineering Department, Chicago, IL, USA, 21 December 2013.

10. Jansto, S. Reheat Furnace Operational Effects on Product Quality. In Proceedings of the AISTech2016, Pittsburgh, PA, USA, 8-11 May 2016.

11. McPherson, N.A.; McLean, A. Continuous Casting; Book Nos. 8; Iron \& Steel Society: Detroit, MI, USA, 1997.

12. Jansto, S. Hot Ductility Characterization of Industrially Cast Microalloyed Steels. In Proceedings of the ABM 46th Steelmaking Conference, Rio de Janeiro, RJ, Brazil, 17-21 August 2015.

13. Mintz, B. Importance of Ar3 Temperature in Controlling Ductility and Width of Hot Ductility Trough in Steels and Its Relationship to Transverse Cracking. Mater. Sci. Technol. 1996, 12, 132-138. [CrossRef] 
14. Jansto, S. Steelmaking and Continuous Casting Process Parameters and Physical Metallurgy Affecting Hot Ductility Behavior of Niobium-Bearing Steels. In Proceedings of the 44th International Congress of the ABM, Araxa, MG, Brazil, 26-29 May 2012.

15. Jansto, S. Carbon Content, Solidification and Strain energy Phenomena Affecting Hot Ductility Behavior during Continuous Casting of Microalloyed Steels. In Proceedings of the 9th European Continuous Casting Conference, Vienna, Austria, 26-29 June 2017.

16. Jansto, S. Continuous Casting Control of Equiaxed-Columnar Transition Zone to Minimize Hot Ductility Induced Cracks. In Proceedings of the AISTech Conference 2018, Philadelphia, PA, USA, 5-8 May 2018.

17. Reeed, R.J. North American Combustion Handbook, 2nd ed.; North American Manufacturing Company: Cleveland, OH, USA, 1978.

18. Jansto, S. MicroNiobium Alloy Approach in Medium and High Carbon Steel Bar, Plate and Sheet Products. In Proceedings of the 15th International Conferences on Advances in Materials and Processing Technologies, Wollongong, Australia, 23-26 September 2012.

19. Engel, W.; Balun, J. Investigation of High Temperature Oxidation of Low-Alloy Steel. Arch. Mater. Sci. Eng. 2014, 69, 19-24.

20. Thakur, P.K. A Review on Efficient Energy Optimization in Reheating Furnaces. In Proceedings of the 16th IRF International Conference, Pune, India, 14 December 2014.

21. Nemethova, J. Structural Changes of C-Mn-Nb-V Steel during the Reheating Acta Metall. Slovaca 2009, 3, 173-179.

22. Matrosov, M.Y.; Golovin, S.V.; Ringinen, D.A.; Ilynsky, V.; Nastich, S.Y.; Kichkina, A.A.; Lyasotsky, I.V. HSLA Steels 2015, Microalloying 2015 E Offshore Engineering Steels 2015; TMS: Pittsburgh, PA, USA, 2015.

23. Jansto, S. Production Comparison of Microalloyed Peritectic and Low Carbon Structural Flat and Long Products. In Proceedings of the 2016 ABM Week, Rio de Janeiro, Brazil, 26-30 September 2016.

24. Jansto, S. New Generation Structural Steel Plate for Meeting Offshore and Arctic Applications. In Proceedings of the 37th International Conference on Ocean, Offshore and Arctic Engineering (OMAE2018 Proceedings), Madrid, Spain, 17-22 June 2018.

(C) 2018 by the author. Licensee MDPI, Basel, Switzerland. This article is an open access article distributed under the terms and conditions of the Creative Commons Attribution (CC BY) license (http://creativecommons.org/licenses/by/4.0/). 